\title{
Acid Base Imbalance in Dialysis: Risk Factors and Impact on Intradialysis Blood Pressure Changes. Findings from a Single Center Prospective Study in Nigeria
}

\author{
Peter Kehinde Uduagbamen* \\ Division of Nephrology and Hypertension, Babcock University Teaching Hospital, Ilishan-Remo, Nigeria.
}

\begin{abstract}
Introduction: Despite improvements in hemodialysis delivery, acid base imbalance is still common in the dialysis population and it is associated with intradialysis blood pressure changes, dialysis termination, inadequacy and poor treatment outcome. We studied acid base imbalance in maintenance hemodialysis, its determinants and relationship with intradialysis blood pressure changes.
\end{abstract}

Materials \& Methods: A prospective study carried out at Babcock University Teaching Hospital, Ilishan-Remo between May 2019 and April 2021 that involved 298 participants who had 1642 hemodialysis sessions.

Results: The mean age was $51.44+7.31$ years, with the females been older than males, $\mathrm{P}=0.04$. The mean predialysis and post dialysis serum bicarbonate were $18.41 \pm 3.63 \mathrm{mmol} / 1$ and $20.61 \pm 6.26 \mathrm{mmol} / 1(\mathrm{P}<0.001)$. The prevalence of pre and post dialysis metabolic acidosis were $79.0 \%$ and $38.3 \%(\mathrm{P}<0.001)$ and of intradialysis hypotension and hypertension were $19.1 \%$ and $25.0 \%(\mathrm{P}=0.02)$. The risk of intradialysis hypotension was negatively correlated with predialysis bicarbonate while intradialysis hypertension was positively correlated with predialysis bicarbonate. The mean dialysis dose was higher in males $(\mathrm{P}=0.03)$. Metabolic acidosis was commoner in elderly and females, and was associated with intradialysis hypotension, dialysis termination and inadequacy. Aging and infrequent dialysis, predicted metabolic acidosis.

Conclusion: Metabolic acidosis is common in maintenance hemodialysis, particularly in females, aged and infrequent dialysis, and leads to intradialysis hypotension, dialysis termination, inadequacy and poor treatment outcome.

Keywords: Metabolic acidosis, Maintenance hemodialysis, Dialysis dose, Intradialysis hypotension, Intradialysis hypertension, Predialysis bicarbonate, Poor treatment outcome.

\section{INTRODUCTION}

Acid base imbalance (ABI) still, common in maintenance hemodialysis (MHD) results from low bicarbonate generation, inadequate dialysis and drugs (phosphate binders) [1]. Metabolic acidosis, the commonest ABI in MHD could be associated with both intradialysis hypotension (IDH) and intradialysis hypertension (IDHT) [2, 3]. Serum bicarbonate concentration (SBC) could be affected by time between sample collection and analysis, and transporting medium [4].

More studies on ABI and intradialysis blood pressure (BP) are needed in view of its implication on treatment outcome. We therefore studied acid base imbalance in maintenance hemodialysis, its determinants and, relationship with intradialysis BP changes.

\section{MATERIALS AND METHODS}

\section{Study Design}

A prospective study conducted at Babcock University Teaching Hospital, Ilishan-Remo, Nigeria, between May 2019 and April 2021.

*Address correspondence to this author at the Division of Nephrology and Hypertension, Babcock University Teaching Hospital, Ilishan-Remo, Nigeria. Email: petr.uduagbamen@gmail.com

\section{Study Population}

Two hundred and ninety eight consented participants, 16 years or older, who had ESRD, according to KDOQI 2012 criteria, on MHD, were consecutively recruited after receiving MHD for at least a month [5].

Patients with renal graft, tumors, infections and sessions less than once weekly were excluded. Between 4 and 6 sessions were studied per participant. Variable retrieved included age, gender, pharyngitis/skin sepsis in childhood, and CKD etiology.

\section{Predialysis Assessment}

The height (in meters) and weight (in kilogram) were measured without shoes, cap or head gear and on light clothing and body mass index (BMI) was calculated by dividing the weight in kilogram by the square of the height in meters $\left(\mathrm{kg} / \mathrm{m}^{2}\right)$. The predialysis oxygen saturation $\left(\mathrm{SPO}_{2}\right)$, pulse rate (PR) and BP, were taken and repeated half hourly. All BP readings were taken manually.

One milliliter of blood was withdrawn from the internal jugular catheter (to confirm patency) and discarded, predialysis samples were taken and arterial and venous ends were 
flushed with heparinized saline. Samples were taken from newly sited femoral catheters, and for arterovenous fistula (AVF), from a vein in contralateral arm.

Participants were connected through arterial, then venous portal. When the blood flow rate (BFR) was altered, the mean was calculated. When IDH or IDHT occurred, vital signs were taken quarter hourly. The dialysate flow rate (DFR) was $500 \mathrm{ml} / \mathrm{min}$ and unfractionated heparin, 5000IU, was the standard anticoagulation dose for most of the sessions. With increased risk of bleeding, heparin dose was reduced or withheld depending on the clotting profile. The dialysate fluid composition was: bicarbonate- $34 \mathrm{mmol} / 1$, sodium- $140 \mathrm{mmol} / 1$, potassium-2mmol $/ 1, \quad$ chloride- $100 \mathrm{mmol} / 1, \quad$ and calcium- $1.25 \mathrm{mmol} / 1$.

Using the stop dialysate flow method, at the end of dialysis time, dialysate flow was stopped and blood flow reduced to $100 \mathrm{ml} / \mathrm{min}$. Five minutes after stopping dialysate flow, blood was taken from the arterial portal, for serum electrolytes (minimizes access recirculation), then hematocrit [6]. Urea reduction ratio (URR) was calculated using pre and post dialysis urea while $\mathrm{Kt} / \mathrm{V}$ was calculated with Daugirdas second generation logarithmic estimation of single pool, using pre and post dialysis urea, ultrafiltration volume, post dialysis weight and dialysis duration [7].

Relating the two formula:

$\mathrm{Kt} / \mathrm{V}=\mathrm{In}(1-\mathrm{URR})$, where In is natural $\log [8]$.

Electrolytes were analyzed using Ion Selective Electrode method and, serum albumin, by bromocresol green method which overestimates it by about $3.5 \mathrm{~g} / \mathrm{dL}$ in renal diseases. Therefore, cut-off values for normal albumin were raised by about 3-3.5 or $5.5-7 \mathrm{~g} / \mathrm{dl}$ compared to the bromocresol purple or the immunophelometric assay respectively [9]. Hematocrit was determined with hematocrit centrifuge.

Participants stopped major meals 2 hours before and through out dialysis to reduce risk of IDH. Monthly means of variables were used for each participant.

\section{DEFINITIONS}

Metabolic Acidosis: SBC $<22 \mathrm{mmol} / 1$ [10].

Interdialytic Weight Gain (IDWG): Predialysis weight minus preceding sessions' post dialysis weight.

Targeted Post Dialysis Weight: Predialysis weight plus administered fluid minus UFV.

Hypertension: $\geq 140 / 90 \mathrm{mmHg}$ [11].

IDH: $>20 \mathrm{mmHg}$ fall in systolic BP with symptoms, without nursing intervention according to the European Best Practices Guidelines (EBPG) [2].

IDHT: $>10 \mathrm{mmHg}$ rise in systolic BP [3].
Anaemia: Hematocrit $<33 \%$ [12].

Hypoalbuminaemia: Albumin $<35 \mathrm{~g} / \mathrm{dL}$ [13].

Very Low Predialysis SBC: $<20.0 \mathrm{mmol} / \mathrm{l}$.

Low Predialysis SBC: 20.0-21.9 mmol/1.

Suboptimal Predialysis SBC: $<22.0 \mathrm{mmol}$.

Normal Predialysis SBC: $\geq 22.0 \mathrm{mmol} / 1$.

Inadequate Dialysis Dose: (Kt/V $<1.2$; URR $<65.0 \%$ ) [14].

Adequate Dose: (Kt/V $\geq 1.2$; URR $\geq 65.0 \%)$ [14].

Hypertension Associated CKD (HACKD): Long standing hypertension complicated by kidney disease, common from middle age upwards.

Chronic Glomerulonephritis (CGN): Kidney disease leading to hypertension in the young and early middle age with or without pharyngitis or skin sepsis in childhood.

Participants with subnormal SBC routinely receive sodium bicarbonate tablets.

\section{STATISTICAL ANALYSIS}

Data was analyzed using Statistical Package for Social Sciences (SPSS) version 22.0 (IBM, CA, USA). Continuous variables were presented as means with standard deviation, compared using paired t-test. Categorical variables were presented as proportions and percentages, compared using Chi square test or Fisher's exact test. Two or more variables were compared using an analysis of variance (ANOVA). A univariate analysis was used to determine the relationship between subnormal predialysis SBC $(<22.0 \mathrm{mmol} / \mathrm{l})$ and participants' variables. Variables with $\mathrm{P}<0.025$ were entered into a multiple regression model to determine independent predictors of subnormal predialysis SBC $(<22.0 \mathrm{mmol} / \mathrm{l})$ using backward elimination to adjust for confounders. Associations between variables were considered to be significant for P-values $<0.05$.

\section{ETHICAL APPROVAL}

This study was approved by the Human Research Ethics Committees of Babcock University, Ilishan-Remo (BUHREC/723/19), and this study followed the tenets of the Helsinki 1975 declaration as revised in 2000 [15].

\section{RESULTS}

A total of 332 patients who had 1812 dialysis sessions during study duration (potentially eligible), were examined. Twenty seven patients were excluded due to presence of any one of: renal graft, tumors, infections or sessions less than once a week. Data for 7 participants (5 males, 2 females) with 38 sessions were missing hence data for 298 participants who had 1642 sessions were analyzed. The mean age of all participants, males and females were $51.44+7.31$ years, $51.2+4.6$ years, and $52.1+2.9$ years respectively, $\mathrm{P}=0.04$. A greater proportion, $121(40.6 \%)$ had hypertension associated chronic 
kidney disease (HACKD) (Table 1). The mean predialysis SBP and DBP were $162.5 \mathrm{mmHg}$ and $99.8 \mathrm{mmHg}$ and were significantly higher than the postdialysis, SBP and DBP, $\mathrm{P}<0.001$ and $\mathrm{P}=0.002$ respectively. Predialysis systolic and diastolic hypertension was found in $84.2 \%$ and $86.9 \%$ sessions. There were significant differences between the mean pre and post dialysis potassium $(\mathrm{P}<0.001)$, bicarbonate $(\mathrm{P}<0.001)$, urea $(\mathrm{P}<0.001)$, creatinine $(\mathrm{P}<0.001)$, eGFR $(\mathrm{P}<0.001)$ and anion gap, $\mathrm{P}<0.001$ (Table 2).

Table 1. Socio-Demographic Characteristics of the Study Population.

\begin{tabular}{|c|c|c|}
\hline Variables & $\begin{array}{c}\text { Frequency (\%) } \\
\text { N=298 (\%) }\end{array}$ & $\begin{array}{c}\text { Dialysis sessions (\%) } \\
\text { N=1642 (\%) }\end{array}$ \\
\hline \multicolumn{3}{|l|}{ Sex } \\
\hline Males & $192(64.4)$ & $1064(64.8)$ \\
\hline Females & $106(35.6)$ & $578(35.2)$ \\
\hline \multicolumn{3}{|l|}{ Ages, Years } \\
\hline $16-44$ & $109(36.5)$ & $527(32.1)$ \\
\hline $45-74$ & $173(58.1)$ & $1064(64.8)$ \\
\hline$\geq 75$ & $16(5.4)$ & $51(3.1)$ \\
\hline \multicolumn{3}{|l|}{ CKD Etiology } \\
\hline Hypertension & $121(40.6)$ & $734(44.7)$ \\
\hline Chronic Glomerulonephritis & $109(36.5)$ & $673(41.0)$ \\
\hline Diabetes & $36(12.1)$ & $127(7.7)$ \\
\hline Others & $32(10.8)$ & $08(6.6)$ \\
\hline \multicolumn{3}{|l|}{ Dialysis Sessions } \\
\hline 1 & $103(34.6)$ & $550(35.5)$ \\
\hline$\geq 2$ & $195(65.4)$ & $1092(64.5)$ \\
\hline \multicolumn{3}{|l|}{ Erythropoietin/Week } \\
\hline 1 & $89(29.9)$ & $524(31.9)$ \\
\hline$\geq 2$ & $209(70.1)$ & $1118(68.1)$ \\
\hline \multicolumn{3}{|l|}{ Body Mass Index, kg/m² } \\
\hline$<25.0$ & $170(57.0)$ & $933(56.8)$ \\
\hline$\geq 25.0$ & $128(43.0)$ & $709(43.2)$ \\
\hline \multicolumn{3}{|l|}{ Oxygen Saturation, \% } \\
\hline$<95$ & $280(94.0)$ & $1447(88.1)$ \\
\hline$\geq 95$ & $18(6.0)$ & $195(11.9)$ \\
\hline \multicolumn{3}{|c|}{ Predialysis Systolic BP, mmHg } \\
\hline$<140$ & $54(18.1)$ & $260(15.8)$ \\
\hline$\geq 140$ & $244(81.9)$ & $1382(84.2)$ \\
\hline \multicolumn{3}{|c|}{ Predialysis Diastolic Blood Pressure, $\mathrm{mmHg}$} \\
\hline$<90$ & $36(12.1)$ & $215(13.1)$ \\
\hline$\geq 90$ & $262(87.9)$ & $1427(86.9)$ \\
\hline
\end{tabular}

BP: Blood Pressure. 
Table 2. Comparison between Pre and Post Dialysis Laboratory Results.

\begin{tabular}{|l|c|c|c|c|}
\hline \multicolumn{1}{|c|}{ Variables } & $\begin{array}{c}\text { Predialysis } \\
\text { Mean (SD) }\end{array}$ & $\begin{array}{c}\text { Post dialysis } \\
\text { Mean (SD) }\end{array}$ & Paired t-test & P-value \\
\hline Sodium, mmol/l & $129.3(4.2)$ & $133.8(2.3)$ & 0.8 & 0.06 \\
\hline Potassium, mmol/1 & $5.5(1.3)$ & $4.1(1.1)$ & 5.8 & $<0.001$ \\
\hline SBC, $\mathrm{mmol} / \mathrm{l}$ & $18.4(3.6)$ & $20.6(6.3)$ & 5.6 & 0.001 \\
\hline Chloride, $\mathrm{mmol} / \mathrm{l}$ & $99.1(2.7)$ & $100.6(7.4)$ & 1.0 & 0.001 \\
\hline Calcium, mmol/1 & $2.1(1.2)$ & $2.3(1.4)$ & 5.0 & $<0.001$ \\
\hline Phosphate, $\mathrm{mmol} / \mathrm{l}$ & $2.1(1.8)$ & $1.8(0.4)$ & 5.4 & $<0.001$ \\
\hline Urea, $\mathrm{mmol} / \mathrm{l}$ & $19.7(3.9)$ & $8.9(3.1)$ & 10.8 & $<0.001$ \\
\hline Creatinine, umol/1 & $842.7(18.4)$ & $417.7(18.3)$ & 9.7 & $<0.001$ \\
\hline GFR, $\mathrm{ml} / \mathrm{min}$ & $6.9(2.1)$ & $11.8(3.5)$ & 8.8 & 0.08 \\
\hline Hematocrit, \% & $24.3(4.3)$ & $25.7(7.3)$ & 0.9 & $<0.001$ \\
\hline Anion $\mathrm{gap}, \mathrm{mEq} / \mathrm{l}$ & $27.5(6.7)$ & $16.9(7.2)$ & 7.2 & \\
\hline
\end{tabular}

GFR: Glomerular Filtration Rate.

Hypobicarbonatemia $(<22.0 \mathrm{mmol} / \mathrm{l})$ was found in $79.00 \%$ and $38.3 \%$ of the pre and postdialysis sessions (Table 3 ). The mean albumin for all, males and females were $33.60 \pm 4.32$ $\mathrm{g} / \mathrm{dl}, 34.92 \pm 3.54 \mathrm{~g} / \mathrm{dl}$ and $30.9 \pm 3.1 \mathrm{~g} / \mathrm{dl}(\mathrm{P}=0.01)$. The predialysis SBC was positively related to the BFR, dialysis duration and dialyzer surface area $(\mathrm{P}<0.001),(\mathrm{P}<0.03)$, $(\mathrm{P}<0.04)$ and negatively related to UFV $(\mathrm{P}<0.001)$. The mean interdialytic weight gain (IDWG) was $3.9 \pm 0.9 \mathrm{~L}$ in sessions with predialysis $\mathrm{SBC}<20.0 \mathrm{mmol} / \mathrm{l}$, was $3.8 \pm 1.0 \mathrm{~L}$ and $3.8 \pm$ $1.7 \mathrm{~L}$ in sessions with predialysis $\mathrm{SBC} 20.0-21.9 \mathrm{mmol} / \mathrm{L}$ and $\geq 22.0 \mathrm{mmol} / 1$ respectively, $\mathrm{P}=0.03$. The mean interdialytic weight gain (IDWG) was $3.9 \pm 1.3 \mathrm{~L}, 4.9 \pm 0.9 \mathrm{~L}$ in sessions with IDH, $3.7 \pm 1.1 \mathrm{~L}$ in IDHT, and $3.9 \pm 1.5 \mathrm{~L}$ in sessions with insignificant $\mathrm{BP}$ change, $\mathrm{P}=0.03$. The mean ultrafiltration volume (UFV) for the study, sessions with IDH, sessions with insignificant BP changes and sessions with IDHT were $3.0 \pm$ $1.1 \mathrm{~L}, 3.9 \pm 0.7 \mathrm{~L}, 2.9 \pm 0.8 \mathrm{~L}$ and $2.5 \pm 0.7 \mathrm{~L}$ respectively.

About $19.1 \%$ of the sessions had IDH while $25.0 \%$ had IDHT and, $61.01 \%$ of IDH occurred in females and $67.52 \%$ of IDHT in males (Table 4). Majority $(56.40 \%)$ of the terminated sessions had predialysis $\mathrm{SBC}<22 \mathrm{mmol} / 1$. The mean dialysis

Table 3. Relationship between Predialysis Serum Bicarbonate and Prescribed Dialysis.

\begin{tabular}{|l|c|c|c|c|c|}
\hline \multicolumn{1}{|c|}{ Variables } & $\begin{array}{c}\text { All Sessions } \\
\text { Mean (SD) }\end{array}$ & $\begin{array}{c}\text { Pre dialysis } \\
<\mathbf{2 0 . 0} \\
\mathbf{m m o l} / \mathbf{l} \\
\mathbf{N = 4 9 3} \\
\text { Mean (SD) }\end{array}$ & $\begin{array}{c}\text { Pre dialysis } \\
\mathbf{2 0 . 0 - 2 1 . 9} \\
\mathbf{m m o l} / \mathbf{l} \\
\mathbf{N = \mathbf { 8 0 4 }} \\
\text { Mean (SD) }\end{array}$ & $\begin{array}{c}\text { Pre dialysis } \\
\mathbf{2 2 . 0} \\
\mathbf{m m o l} / \mathbf{l} \\
\mathbf{N = 3 4 5} \\
\text { Mean (SD) }\end{array}$ & ANOVA \\
\hline Blood flow rate ml/min & $356.5(6.8)$ & $316.3(8.7)$ & $366.3(12.8)$ & $392.5(18.6)$ & $<0.001$ \\
\hline Dialysis duration $(\mathrm{hrs})$ & $3.9(1.7)$ & $3.8(1.2)$ & $3.9(0.3)$ & $3.9(0.2)$ & 0.03 \\
\hline Surface area, $\mathrm{m}^{2}$ & $1.7(1.1)$ & $1.7(1.4)$ & $1.7(1.0)$ & $1.8(0.2)$ & 0.04 \\
\hline Ultrafiltration vol. liter & $3.0(1.1)$ & $3.7(1.4)$ & $3.2(0.6)$ & $1.9(0.8)$ & $<0.001$ \\
\hline
\end{tabular}

PDSBC: Predialysis Serum Bicarbonate Concentration.

Table 4. Relationship between Predialysis Serum Bicarbonate and Intradialysis Events and Outcome.

\begin{tabular}{|l|c|c|c|c|c|}
\hline \multicolumn{1}{|c|}{ Variables } & $\begin{array}{c}\text { Frequency } \\
\mathbf{N = 1 6 4 2} \\
\text { Mean (SD }\end{array}$ & $\begin{array}{c}\text { Intradialysis } \\
\text { Hypotension } \\
\text { N=314 } \\
\text { Mean (SD) }\end{array}$ & $\begin{array}{c}\text { Insignificant } \\
\text { BP Change } \\
\text { N=917 } \\
\text { Mean (SD) }\end{array}$ & $\begin{array}{c}\text { Intradialysis } \\
\text { Hypertension } \\
\text { N=411 } \\
\text { Mean (SD) }\end{array}$ & ANOVA \\
\hline Mean Pre dialysis, mmol/1 & $18.4(3.6)$ & $16.7(2.4)$ & $18.3(3.1)$ & $19.9(4.8)$ & 0.003 \\
\hline Mean Kt/V & $1.16(0.5)$ & $1.10(0.2)$ & $1.2(0.4)$ & $1.12(0.5)$ & 0.03 \\
\hline Mean URR\% & $59.6(12.0)$ & $56.9(9.3)$ & $61.1(4.8)$ & $58.3(11.6)$ & 0.04 \\
\hline
\end{tabular}

URR: Urea Reduction Ratio. 
dose was $1.16 \pm 0.51$, highest in sessions with insignificant BP change and lowest in sessions with IDH, $\mathrm{P}=0.03$ Dialysis dose was adequate in $13.10 \%$ of the sessions.
From univariate analysis (Table 5), the mean predialysis SBC was significantly higher in males than females $(\mathrm{P}=0.04)$, was positively related to dialysis frequency, $(\mathrm{P}<0.001)$, and was

Table 5. Univariate Analysis of Factors Associated with Suboptimal Predialysis Bicarbonate.

\begin{tabular}{|c|c|c|c|c|c|}
\hline Variables & $\begin{array}{c}\text { Predialysis } \\
\text { SBC } \\
<22.0 \\
\text { mmol/l } \\
\text { N=1297(\%) }\end{array}$ & $\begin{array}{c}\text { Predialysis } \\
\text { SBC } \\
\geq 22.0 \\
\text { mmol } / \mathbf{l} \\
\text { N=345(\%) }\end{array}$ & OR & $95 \% \mathrm{CI}$ & P-value \\
\hline \multicolumn{6}{|l|}{ Gender } \\
\hline Males & $833(78.29)$ & $231(21.71)$ & \multirow[t]{2}{*}{1.88} & \multirow[t]{2}{*}{$0.45-1.96$} & \multirow[t]{2}{*}{0.04} \\
\hline Females & $464(80.28)$ & $114(19.72)$ & & & \\
\hline \multicolumn{6}{|l|}{ Age, Years } \\
\hline$<75$ & $1253(78.8)$ & $338(21.2)$ & \multirow[t]{2}{*}{5.4} & \multirow[t]{2}{*}{$1.24-8.74$} & \multirow[t]{2}{*}{$<0.001$} \\
\hline$\geq 75$ & $44(86.3)$ & $7(13.7)$ & & & \\
\hline \multicolumn{6}{|l|}{ CKD Etiology } \\
\hline Diabetes & $97(85.8)$ & $16(14.2)$ & \multirow[t]{2}{*}{3.7} & \multirow[t]{2}{*}{$2.04-3.79$} & \multirow[t]{2}{*}{0.03} \\
\hline Non-diabetic & $1200(78.5)$ & $329(21.5)$ & & & \\
\hline \multicolumn{6}{|c|}{ Dialysis Sessions/wk } \\
\hline 1 & $526(95.6)$ & $24(4.4)$ & \multirow[t]{2}{*}{8.5} & \multirow[t]{2}{*}{$0.93-11.71$} & \multirow[t]{2}{*}{$<0.001$} \\
\hline$\geq 2$ & $771(70.6)$ & $321(29.4)$ & & & \\
\hline \multicolumn{6}{|l|}{$\mathrm{SPO}_{2}$} \\
\hline$<95$ & $1294(99.8)$ & $153(0.2)$ & \multirow[t]{2}{*}{9.4} & \multirow[t]{2}{*}{$2.58-13.89$} & \multirow[t]{2}{*}{$<0.001$} \\
\hline$\geq 95$ & $3(1.5)$ & $192(98.5)$ & & & \\
\hline \multicolumn{6}{|c|}{ Systolic BP, mmHg } \\
\hline$<140$ & $43(16.5)$ & $217(83.5)$ & \multirow[t]{2}{*}{5.6} & \multirow[t]{2}{*}{1.53 .6 .16} & \multirow[t]{2}{*}{$<0.001$} \\
\hline$\geq 140$ & $1254(90.7)$ & $128(9.3)$ & & & \\
\hline \multicolumn{6}{|c|}{ PD Sodium, mmol/l } \\
\hline$<135$ & $1278(83.8)$ & $247(16.2)$ & \multirow[t]{2}{*}{1.2} & \multirow[t]{2}{*}{$0.89-1.72$} & \multirow[t]{2}{*}{0.05} \\
\hline$\geq 135$ & $19(16.2)$ & $98(83.8)$ & & & \\
\hline PD Potassium, n & & & & & \\
\hline$\leq 5.5$ & $264(92.6)$ & $21(7.4)$ & 2.6 & $0.11-3.41$ & 0.02 \\
\hline$>5.5$ & $1033(76.1)$ & $324(23.9)$ & & & \\
\hline PD Creatinine, & & & & & \\
\hline$<500$ & $197(49.5)$ & $134(40.5)$ & 5.0 & $1.09-6.33$ & $<0.001$ \\
\hline$\geq 500$ & $1100(83.9)$ & $211(16.1)$ & & & \\
\hline GFR, ml/min & & & & & \\
\hline$<5$ & $295(68.9)$ & $133(31.1)$ & 3.6 & $0.71-3.38$ & 0.001 \\
\hline$\geq 5.0$ & $802(79.1)$ & $212(20.9)$ & & & \\
\hline Hematocrit,\% & & & & & \\
\hline$<33.0$ & 1185 (93.7) & $79(6.3)$ & 6.6 & $5.84-10.42$ & $<0.001$ \\
\hline$\geq 33.0$ & $112(29.6)$ & $266(70.4)$ & & & \\
\hline $\mathrm{Kt} / \mathbf{V}$ & & & & & \\
\hline$<1.2$ & $1271(89.1)$ & $156(10.9)$ & 5.8 & $3.69-8.11$ & $<0.001$ \\
\hline$\geq 1.2$ & $26(12.1)$ & $189(87.9)$ & & & \\
\hline
\end{tabular}

PDSBC: Predialysis Serum Bicarbonate Concentration, BP: Blood Pressure. 
negatively related to the age and creatinine, $\mathrm{P}<0.001$ and $\mathrm{P}<0.001$. From multivariate regression analysis (Table 6) dialysis frequency, $\mathrm{SPO}_{2}$, potassium, urea and hematocrit independently predicted metabolic acidosis.

Table 6. Multivariate Regression Analysis Showing Predictors of Metabolic Acidosis.

\begin{tabular}{|l|c|c|c|}
\hline \multicolumn{1}{|c|}{ Variables } & aOR & $\mathbf{9 5 \%}$ CI & P-value \\
\hline Age, Years & 0.04 & $0.039-0.051$ & 0.06 \\
\hline Dialysis Frequency & 7.72 & $1.59-8.32$ & $<0.001$ \\
\hline Erythropoietin & 1.02 & $0.16-1.18$ & $<.06$ \\
\hline PD Percent Oxygen Saturation & 5.18 & $2.04-9.64$ & 0.001 \\
\hline PD Systolic Blood Pressure, $\mathrm{mmHg}$ & 3.33 & $1.26-3.99$ & 0.05 \\
\hline PD Diastolic Blood Pressure, $\mathrm{mmHg}$ & 2.96 & $2.93-4.13$ & 0.001 \\
\hline PD Potassium, mmol/1 & 4.68 & $1.57-6.22$ & $<0.001$ \\
\hline PD Urea, mmol/1 & 6.35 & $2.14-8.43$ & 0.03 \\
\hline PD Creatinine, umol/1 & 3.23 & $0.12-4.53$ & 0.04 \\
\hline Glomerular Filtration Rate, $\mathrm{ml} / \mathrm{min}$ & 3.42 & $2.32-3.52$ & $<0.001$ \\
\hline Hematocrit, \% & 6.02 & $0.01-6.95$ & \\
\hline
\end{tabular}

aOR: Adjusted Odd Ratio, CI: Confidence Interval, PD: Predialysis.

\section{DISCUSSION}

The prevalence of predialysis and post dialysis MA were $79.0 \%$, and $38.3 \%$, with IDHT commoner than IDH. Our finding mirrors findings by Raphael et al. [10] who found a prevalence of $80 \%$ in CKD stage 5, using a SBC $<22.0 \mathrm{mmol} / 1$ but higher than the $68.85 \%$ found by Sajgure et al. [1] using a SBC cut-off of $22.0 \mathrm{mmol} / \mathrm{l}$, and lower than the $94.7 \%$ found by Oliveira et al. [16] who used a SBC cut-off of $22.0 \mathrm{mmol} / \mathrm{l}$. Considering the impact of MA on dialysis outcome and the quality of life of patients on MHD, the KDOQI recommendation of a minimum predialysis $\mathrm{SBC}$ of $22.0 \mathrm{mmol} / \mathrm{l}$ is justified [17].

The prevalence of IDH of $19.1 \%$ is higher than $17.2 \%$ found by Sands et al. [18] using a SBP fall of $>30 \mathrm{mmHg}$. A SBP fall of $>30 \mathrm{mmHg}$ in this study, would have given a lower prevalence of IDH. Metabolic acidosis depresses myocardial contractility, reduces the effective blood volume (EBV) through cutaneous vasodilatation, thereby increasing the risk of IDH and ultimately, inadequate dialysis which impacts negatively on quality of life (QOL), morbidity and mortality, particularly with SBP dropping to a nadir $<90 \mathrm{mmHg}[19,20]$. The concurrent DBP drop cause myocardial hypo perfusion and can lead to myocardial ischemia, stunning and cardiac fibrosis [21].

Our study's IDHT prevalence of $25.0 \%$ was higher than the $19.7 \%$ found by Raikou et al. [3]. The wide difference could be attributed to the lower dialysis dose in our study population. The higher prevalence of IDHT over IDH agree with findings in a local study that found prevalence of $45.3 \%$ and $31.3 \%$ respectively [22]. As ultrafiltration compromises cardiac output $(\mathrm{CO})$, volume replacement during the initial steep slope of the Frank Sterling Curve (FSC) augments the systolic and diastolic functions resulting in increased stroke volume (SV) and CO preventing fall in BP. However, volume replacement in plateau phase reduces $\mathrm{SV}$ and cardiac output [23]. Park et al. found a 'J' or ' U' shaped relationship between peridialytic BP variations and cardiovascular outcome [24].

Our finding of greater male predominance agrees with findings of a female bias in accessing health care in Nigeria [7]. It also partly explains the lower mean age of males at dialysis initiation [25].

We attribute the inverse relationship between MA and albumin to the low oncotic pressure causing endothelial microcirculatory dysfunction with albuminuria [26]. Loop and thiazides diuretics, calcium based phosphate binders and bicarbonate supplementation can induce transient Malk and ameliorate acidosis [27]. High dialysate bicarbonate could lead to chronic alkalemia although dialysate bicarbonate of 40-42 $\mathrm{mmol} / \mathrm{l}$ is considered safe and beneficial. Having used a dialysate bicarbonate of $34 \mathrm{mmol} / \mathrm{L}$ in this study, a reasonable level of acid buffering would have been achieved [28]. Sevelamer use worsens MA through the 1:1 chloride buffering by bicarbonate [29].

We encountered some limitations in this study. We were unable to determine participants' dry weight, the residual kidney function and its contribution to the dialysis dose. Despite being a better measure in assessing ABI, blood PH was not done on account of cost In addition, the presence of some co-morbidities/confounders could not be ruled out, just as some dialysis interval were not regular. Compliance with directives to avoid heavy meals two hours prior to dialysis and 
adherence to drug use were difficult to ascertain. The relatively large sample size contributed to the strength of the study.

\section{CONCLUSION}

The risk factors for MA included aging, females, infrequent dialysis, lower GFR, temporary catheters and shortened dialysis time. MA was associated with IDH, as IDHT (which was commoner than IDH) was associated with anemia. Targeting a predialysis $\mathrm{SBC}$ of $>22.0 \mathrm{mmol} / \mathrm{l}$ will significantly improve dialysis dose and treatment outcome.

\section{CONFLICT OF INTEREST}

Declared none.

\section{ACKNOWLEDGEMENTS}

The author thankfully acknowledge the professional guidance by Ms. Maria Baig, Editorial Manager of National Journal of Health Sciences, in the processes through the review and revision of this article. The author appreciates the contribution of the nursing, technical and supporting staffs of the dialysis suite of Babcock University Teaching Hospital, Ilishan-Remo, towards the success of this study.

\section{REFERENCES}

[1] Sajgure AD, Dighe TA, Korpe JS, et al. Prevalence and severity of metabolic acidosis in patients on maintenance hemodialysis in India. Med J D.Y. Patel Univ 2016; 9(6): 716-720. DOI: $10.4103 / 0975-2870.194189$

[2] Kooman J, Basci A, Pizzarelli F, et al. European Best Practices Guidelines (EBPG) on hemodynamic instability. Nephrol Dial Transplant 2007; 22(suppl 2): ii2-ii44.

[3] Raikou VD, Kyriaki. The Association between intradialytic hypertension and metabolic disorders in end stage renal disease. Int J Hypertens 2018; 2018: 1681056. DOI: $10.1155 / 2018 / 1681056$

[4] Kirschbaum B. Spurious metabolic acidosis in hemodialysis patients. Am J Kidney Dis 2000; 35: 1068-71. DOI: 10.1016/S0272-6386(00)70041-2

[5] National Kidney Foundation. KDOQI Clinical Practice Guideline for Diabetes and CKD: 2012 update. Am J Kidney Dis 2012; 60(5): 850-86. DOI: 10.1053/j.ajkd.2012.07.005

[6] Geddes CC, Traynor J, Walbaum D, Fox JG, Mactier RA. A new method of post-dialysis blood urea sampling: The 'stop dialysate flow' method. Nephrol Dial Trans 2000; 15(4): 517-23. DOI: $10.1093 / \mathrm{ndt} / 15.4 .517$

[7] Daugirdas JT. Second generation logarithmic estimates of single-pool variable volume $\mathrm{Kt} / \mathrm{V}$ : An analysis of error. J Am Soc Nephrol 1993; 4: 1205-13. DOI: 10.1681/ASN.V451205

[8] Virga G, Gardin C, Mastrosimone S, Bonadonna A. Relationship between urea reduction ratio (URR) and K/V in hemodi- alysis. 2002; 52(4): 325-6. DOI: 10.5414/CNP57325

[9] Clase CM, St Pierre MW, Churchill DN. Conversion between bromocresol green - and bromocresol purple-measured albumin in renal disease. Nephrol Dial Trans 2001; 16: 1925-9. DOI: $10.1093 / \mathrm{ndt} / 16.9 .1925$

[10] Raphael KL, Zhang Y, Ying J, Greene T. Prevalence of and risk factors for reduced serum bicarbonate in chronic kidney disease. Nephrology (Carlton) 2014; 19(10): 648-54. DOI: 10.1111/nep. 12315

[11] Phan O, Burnier M, Wuerzner G. Hypertension in chronic kidney disease - role of arterial calcification and impact on treatment. Eur Cardiol 2014; 9(2): 115-9. DOI: 10.15420/ecr.2014.9.2.115

[12] Mikhail A, Brown C, Williams JA, et al. Renal association clinical practice guideline on anaemia of chronic kidney disease. BMC Nephrol 2017; 18: 345. DOI: 10.1186/s12882-017-0688-1

[13] Zhang J, Zhang R, Wang Y, et al. The level of serum albumin is associated with renal prognosis in patients with diabetic nephropathy. J Diabaets Res 2019; 2019: 7825804. DOI: $10.1155 / 2019 / 7825804$

[14] El-Sheikh M, El-Ghazaly G. Assessment of hemodialysis adequacy in patients with chronic kidney disease in the hemodialysis unit at Tanta University Hospital in Egypt. Indian J Nephrol 2016; 26(6): 398-404. DOI: 10.4103/0971-4065.168141

[15] Hosmer DW, Lameshow S. Applied Logistic Regression. $2^{\text {nd }}$ ed. New York N.Y.: Wiley 2000; p. 95 DOI: $10.1002 / 0471722146$

[16] World Medical Association Declaration of Helsinki 2000. Ethical principles for medical research involving human subjects. 2000; Available at: https://www.wma.net/wp-content/uploads/2016/11/DoH-Oct2000.pdf. [Accessed on April 29, 2020].

[17] Oliveira CMC, Vidal CLC, Cristino EF, Pinheiro FM, Kubrusly M. Metabolic acidosis and its association with nutritional status in hemodialysis. J Bras Nephrol 2015; 37(4): 458-66. DOI: $10.5935 / 0101-2800.20150073$

[18] National Kidney Foundation. KDOQI clinical practice guidelines for bone metabolism and disease in chronic kidney disease. Am J Kidney Dis 2003; 42(4 Suppl 3): S1-201.

[19] Sands JS, Usvyat LA, Sullivan T, et al. Intradialytic hypotension: Frequency, sources of variation and correlation with clinical outcome. Hemodial Int 2014; 18(2): 415-22. DOI: 10.1111/hdi.12138

[20] Inrig JK, Oddone EZ, Hasselblad V, et al. Association of intradialytic blood pressure changes with hospitalization and mortality rates in prevalent ESRD patients. Kidney Int 2007; 71: 454-61. DOI: 10.1038/sj.ki.5002077 
[21] Yoshihara F, Kishida M, Ogawa K, et al. High stroke volume variation is an independent predictor for decreased blood pressure during hemodialysis therapeutic apharesis and dialysis. Ther Apher Dial 2017; 21(2): 166-72. DOI: 10.1111/1744-9987.12511

[22] Locatelli F, Stefoni S, Petitclerc T, et al. Effect of a plasma sodium biofeedback system applied to HFR on the intradialytic cardiovascular stability. Results from a randomized controlled study. Nephrol Dial Trans 2012; 27: 3935-42. DOI: 10.1093/ndt/gfs091

[23] Okpa HO, Effa EE, Oparah SK, et al. Intradialysis blood pressure changes among chronic kidney disease patients on maintenance haemodialysis in a tertiary hospital IN South south Nigeria: A 2 year retrospective study. Pan Afr Med J 2019; 33: 91. DOI: 10.11604/pamj.2019.33.91.17000

[24] Park J, Rhee CM, Sim JJ, et al. A comparative effectiveness research study of the change in blood pressure during hemodialysis treatment and survival. Kidney Int 2013; 84: 795-802. DOI: $10.1038 / \mathrm{ki} .2013 .237$
[25] Casimir G, Lefevre N, Corazza F, Duchateau J, Chamekh M. The acid-base balance and gender in inflammation. A mini-review. Front Immunol 2018; 9: 475. DOI: 10.3389/fimmu.2018.00475

[26] Kraut JA, Madias NE. Metabolic Acidosis of CKD: An Update. Am J Kidney Dis 2016; 67: 307-17. DOI: 10.1053/j.ajkd.2015.08.028

[27] Ellison DH. Clinical Pharmacology in Diuretic Use. Clin J Am Soc Nephrol 2019; 14(8): 1248-57. DOI: 10.2215/CJN.09630818

[28] Kalantar-Zadeh K. Moderator's view: Higher serum bicarbonate in dialysis patients is protective. Nephrol Dial Trans 2016; 31(8): 1231-4. DOI: $10.1093 / \mathrm{ndt} / \mathrm{gfw} 258$

[29] Rabbani SA, Sridhar SB, Rao PGM, Kurian MT, Essawy BE. Use of phosphate binders in end-stage renal disease: An Experience from a secondary care hospital in United Arab Emirates. J Pharm Allied Sci 2019; 11(2): 148-54. DOI: 10.4103/JPBS.JPBS_290_18 